\title{
Divergence of Values and Goals in Participatory Research
}

Lucas Dunlap, Amanda Corris, Melissa Jacquart, Zvi Biener, Angela Potochnik

\author{
Pre-print
}

Forthcoming, Studies in History and Philosophy of Science

Special Issue: Values and Pluralism in the Environmental Sciences: From Inferences to

Institutions

\begin{abstract}
Public participation in scientific research has gained prominence in many scientific fields, but the theory of participatory research is still limited. In this paper, we suggest that the divergence of values and goals between academic researchers and public participants in research is key to analyzing the different forms this research takes. We examine two existing characterizations of participatory research: one in terms of public participants' role in the research, the other in terms of the virtues of the research. In our view, each of these captures an important feature of participatory research but is, on its own, limited in what features it takes into account. We introduce an expanded conception of norms of collaboration that extends to both academic researchers and public participants. We suggest that satisfying these norms requires consideration of the two groups' possibly divergent values and goals, and that a broad characterization of participatory research that starts from participants' values and goals can motivate both public participants' role in the research and the virtues of the research. The resulting framework clarifies the similarities and differences among participatory projects and can help guide the responsible design of such projects.
\end{abstract}

\section{Introduction}

Public participation in the conduct of scientific research has been gaining prominence in many fields of science. It has also caught the attention of scholars in science and technology studies. Different disciplines refer to this kind of research using varied terminology: "citizen science", "community science", "public participation in scientific research", "community-based participatory research", "action research," and others. Here we use the generic term 'participatory research', sometimes abbreviated to 'PR,' for any of these forms of public participation in scientific research. But we should note that the terminological variation reflects not only different fields of research but also importantly different research traditions (Ottinger, 
2017). ${ }^{1}$ There is much variety in how members of the public are included in research efforts and to what end. See Table 1 for an attempt to categorize at least a sampling of this variety.

\begin{tabular}{|l|l|l|}
\hline Participatory Approach & Characteristics & Typical Field(s) \\
\hline citizen science & community participation in data collection & $\begin{array}{l}\text { environmental } \\
\text { science, astronomy }\end{array}$ \\
\hline community science & $\begin{array}{l}\text { research partnerships with the community } \\
\text { to further community-held goals }\end{array}$ & $\begin{array}{l}\text { community } \\
\text { psychology }\end{array}$ \\
\hline $\begin{array}{l}\text { community-based } \\
\text { participatory research }\end{array}$ & $\begin{array}{l}\text { community participation in every stage of } \\
\text { research from designing the research } \\
\text { questions to disseminating findings }\end{array}$ & health \\
\hline action research & $\begin{array}{l}\text { community participation in every stage of } \\
\text { research; focused on producing social } \\
\text { change }\end{array}$ & $\begin{array}{l}\text { social science and } \\
\text { education }\end{array}$ \\
\hline emancipatory research & $\begin{array}{l}\text { focus on shifting power from researchers } \\
\text { to community participants }\end{array}$ & disability research \\
\hline
\end{tabular}

Table 1: a sampling of participatory research approaches with a brief characterization and indication of the field(s) in which they are typical. This table draws from the much more comprehensive Table 1 in (Vaughn \& Jacquez 2020).

Consider, as an initial example of participatory research, Galaxy Zoo. Galaxy Zoo is a large-scale voluntary participation project in which members of the public log on to a public website and help categorize images of galaxies by shape. To date, volunteers have helped categorize over 110 million galaxies (Raddick et al. 2009). On the other end of the spectrum is Latinos Unidos por la Salud (LU-Salud). LU-Salud is a joint effort of a team of academic researchers at the University of Cincinnati and eight Latina women from Cincinnati (Vaughn et al., 2017; Jacquez, Vaughn \& Suarez-Cano, 2018). They aim to better understand the health needs of the growing local population of Latinx immigrants and help formulate workable

\footnotetext{
${ }^{1}$ See (Vaughn and Jacquez 2020) for a fuller discussion of the terminological variation and associated differences in approach. Their Table 1 also provides a more comprehensive index of participatory research approaches than our table does.
} 
interventions. Throughout this paper, we will rely on these two projects as our primary examples of PR. We choose these because they differ in almost every aspect and exemplify PR projects from different disciplines and participatory research traditions. Across this spectrum, participants are involved in scientific research to various degrees and in various ways; the extent of their involvement, the aims of that involvement, and the epistemic and ethical consequences all vary.

Proposals have been made about how to categorize and understand the design of participatory research projects, but the theory of participatory research is still limited. One significant constraint on the theory is that it must encompass radically different types of projects, in which the nature and goals of public participation range from 'mere' data collection, to activist promotion of existing research, to the initiation of research projects themselves. In this paper, we develop a general framework for analyzing and categorizing participatory research projects across this wide spectrum. We do so as philosophers of science. Our primary experience and expertise are in philosophical analysis. By 'philosophical analysis' we mean the drawing out of logical and conceptual implications embodied in working distinctions, assumptions, and hypotheses. Our study is therefore not motivated by empirical research or by a meta-analysis of existing publications on PR. Rather, we examine two approaches to PR in order to articulate and discover their logical and conceptual interconnections. Our framework highlights what we take to be PR's central characteristic, namely, that it is a collaboration between groups of people whose values and goals commonly diverge from one another. This characteristic is underemphasized by other theoretical accounts of participatory research. As our discussion will show, the divergence of values and goals is central because it both distinguishes participatory research from other scientific research and also is key to making sense of the variety of participatory approaches. Given this divergence of goals and values, participatory research should be developed with special attention to how norms of collaboration apply.

We begin in $\S 2$ by outlining two existing approaches to the theory of PR. The first—by Shirk et al. (2012) — categorizes PR projects according to the degree and type of public participation they exemplify. The second — by Kimura and Kinchy (2016) — argues that Shirk et al.'s typological approach is overly restrictive. They instead suggest a focus on the virtues that PR projects exemplify, which they understand as the various reasons for valuing and engaging in those projects. Their categorization scheme cuts across that of Shirk et al. However, virtue, as they use it, is itself a multi-faceted concept. Their list of virtues includes a mix of ethical, 
practical, and epistemic reasons for valuing public participation from the points of view of either the researchers or public participants, without tracking the difference. While we adopt the working definition of a PR virtue from Kimura and Kinchy_namely, a reason to engage in PR — we will further distinguish between virtues that are primarily ethical, practical, or epistemic and will also highlight the perspectival nature of virtues.

Of course, Shirk et al.'s and Kimura and Kinchy's taxonomies are both useful. However, we believe that they can be fruitfully extended and brought into conversation with one another by recognizing the divergence of goals and values that typifies participatory research. In $\S 3$, we argue that the kinds of reasons Kimura and Kinchy's virtues provide, as well as their relative importance, depends on who is evaluating them. Any list of virtues that a given PR project exemplifies is incomplete if it does not include the further specification: for whom are these virtues, and in light of what values and goals? Adding this dimension to Kimura and Kinchy's account enables us to state the core issue which our framework aims to address: when the goals and values of scientists and members of the public diverge radically, they may yield evaluations of the same project that are incompatible or at least in serious tension with one another. Yet, given that PR projects are collaborations, we argue that norms of collaboration apply and can help bridge researchers' and participants' divergent views. In $\S 4$, we detail the norms operative in more traditional research collaboration contexts and discuss how these should be expanded to apply to participatory research. In $\S 5$ we suggest how this divergence of goals also influences the considerations upon which Kimura and Kinchy and Shirk et al. focus, namely, the virtues of a PR project and the degree of public participation.

We believe the framework that results from our analysis clarifies the similarities, differences, and relative success of different participatory research projects. As philosophers of science, our interest in this topic is conceptual. We argue for a framework that, like the works cited above, is descriptively and explanatorily adequate, but, unlike them, it portrays PR in terms that are as general as possible; namely, as a species of collaborative action. We aim to find what we can learn about PR from this admittedly abstract vantage point. Of course, we do not deny the value and utility of other descriptive frameworks. The approach developed in this paper draws significantly on Shirk's and Kimura and Kinchy's frameworks, but for the purpose of synthesizing and generalizing them. The result is that we end up highlighting what we take to be 
the most important feature shared by diverse kinds of PR projects insofar as they are instances of collaborative action; namely, that they are beholden to norms of collaboration. This component of our analysis leads to the possibility of using this framework normatively, as a guide for how PR projects ought to be designed and implemented, though that project will be left to future work.

\section{Two Participatory Research Taxonomies}

Shirk et al. (2012) and Kimura and Kinchy (2016) each develop distinct frameworks for the classification and deliberate design of participatory research. According to Shirk et al., five features guide classification and further design of PR: the inputs (interests of the public and scientific community), activities (design and execution of the research project), outputs (the research data and the experiences of participants), outcomes (skills or knowledge that result for science or participants, resulting interventions), and the impacts (long-term value of the research). These elements shape the desired degree of public participation-number and diversity of participants, duration of involvement, and depth of participation-as well as the quality of participation, that is, context-relative judgments of how meaningfully and ethically participants are involved. Shirk et al. use these five features to describe design choices involved in models of participatory research (see also Bonney et al. 2009). They are ordered by increasing degree of public participation: (i) Contributory projects, which are generally designed by scientists and members of the people contribute; (ii) Contractual projects, in which communities contract scientists to conduct research; (iii) Collaborative projects, which are generally designed by scientists but allow the public to have some control of research questions; (iv) Co-created projects, which at least some of the public are active in all aspects of the research including design and management; and (v) Collegial contributions, where "non-credentialed individuals conduct independent research with varying degrees of expected recognition" (29). On this typology, Galaxy Zoo, the PR project in which members of the public help sort galaxy images by shape, is classified as a contributory project, given that data sets are collected and set up by the scientists. Latinos Unidos por la Salud, the PR project focused on addressing health needs of 
Cincinnati's Latinx community, is co-created, with both the community members and social scientists designing the surveys and research questions together.

Shirk et al. intend their typology to guide research teams in designing research projects and, especially, in determining the nature and extent of public inclusion. But they acknowledge that the typology has limitations. Some projects may not be clearly categorized. As they say, "In general, typologies of participation and project design are best considered tools for understanding trends, as practice inevitably 'blurs boundaries'” (29). Further, there are limitations to how this taxonomy can guide research practices, for "every initiative arises in a unique context, in response to different needs, meaning prescribed approaches are unreasonable" $(29) .^{2}$

Kimura and Kinchy (2016) are critical of Shirk et. al.'s approach, or any typology that "focuses on participation as the defining virtue of [PR]" (332). In their view, these only "highlight one feature of [PR] while ignoring other dimensions that may be more significant for participants or their challengers" (338). Against Shirk's typology in particular, Kimura and Kinchy note that some PR projects may be valuable while also exhibiting a low degree of participation, such as non-profit advocacy organizations that produce socially valuable research without directly requiring participatory help. But again, their general concern is with any typology that focuses on just one dimension of participatory research--such as project goals (Wiggins and Crowston 2010) or responsibility for initiating projects (Moore 2006).

In order to account for the multiple dimensions along which PR projects can be analyzed, Kimura and Kinchy shift focus to a set of virtues common in the literature as motivations for PR. They say these virtues are "the reasons why both advocates and analysts of [PR] contend that it is socially valuable" (339). By focusing on virtues, their hope is to highlight the similarities and connections between PR projects that may be categorized differently in a typology that relies only on degree of public participation. Revealing these similarities further highlights the fact that PR projects can be valued for reasons other than the mere fact that they involve the public.

\footnotetext{
${ }^{2}$ See also (Cornwall 2008, Wiggins and Crowston 2010).
} 
Kimura and Kinchy list seven virtues, noting that the list is not exhaustive and that some of the virtues are contradictory and cannot be jointly exemplified by the same project (33). They are: (1) Increasing scientific data; (2) Increasing citizens' scientific literacy and awareness; (3) Building community capacity for environmental protection; (4) Building more equal relationships between scientists and citizens; (5) Filling knowledge gaps and challenging official accounts; (6) Driving policy change; and (7) Catching polluters.

This list demonstrates one strength of Kimura and Kinchy's account; namely, they stress that PR projects take place in a social and political context that extends beyond the community of scientists and public collaborators directly involved. Certainly, examining PR projects for their social, political, and ethical implications is crucial to understanding them, and this aspect of PR should be taken into consideration in analyzing and designing future projects. But Kimura and Kinchy also hold that the virtues of PR projects stem from the projects' ethical impact in this larger context. This is part of their conception of virtues, which are "the reasons why both advocates and analysts of [participatory research] contend that it is socially valuable" (339, emphasis added).

We think Kimura and Kinchy's emphasis on the socio-political and ethical virtues of participatory research is important. But we think it results in the deemphasis of other equally important virtues; particularly epistemic and practical ones. Take epistemic virtues first. While Kimura and Kinchy do treat 'increasing scientific data' as an epistemic good, they nevertheless analyze it primarily through the lens of sociopolitics. For example, they ask whether it is ethically permissible to sidestep the problem of insufficient funding for data-collection by utilizing participants as unpaid labor. They also easily juxtapose "filling knowledge gaps" with “challenging official accounts", thereby melding epistemic and sociopolitical concerns.

In contrast, we would like to consider epistemic virtues of participatory research as virtues in their own right. In fact, we take Kimura and Kinchy's concern with balancing the epistemic and social-justice benefits of PR as evidence that these benefits can be considered separately (which is not to say in isolation) from one another. PR can have epistemic value as well as sociopolitical value; there need not be a tradeoff between the quality of science and the participation of the public. Further, the range of epistemic virtues is wider than Kimura and 
Kinchy's list suggests. For example, certain massive-scale data collection and processing projects are arguably only possible with wide participation from the public and broad geographic distribution. So, an epistemic virtue of some PR projects lies in their capacity for enabling access to data in the first place. For instance, without the help of public participants, data on phenomena like large-scale bird migration patterns (Sullivan et al. 2009) would be difficult to obtain. This appears to be a distinct advantage to these types of projects and is worth emphasizing as an epistemic virtue of PR.

Participatory research also has what we call 'practical' virtues that can be considered alongside epistemic and social-justice virtues. For instance, PR projects can promote the professional standing and well-being of participants (whether justly or not) and can help solve problems that are not of a pressing social-justice or ecological nature (Kimura and Kinchy's sole focuses). Galaxy Zoo, for example, may increase a participant's well-being by promoting a sense of belonging to a larger community or simply by providing mental stimulation. These benefits are real but are neither ethical nor epistemic. We call them 'practical' because they improve one's life -- or, if you will, aid in the practice of life -- but are aimed neither at the satisfaction of moral norms nor at increasing knowledge. Thus, in our view, consideration of the virtues of PR should be multi-dimensional, taking into account epistemic and practical as well as ethical virtues. ${ }^{3}$

Given the complexity of participatory research, it's no surprise that systematic accounts must highlight some features of PR and downplay others. ${ }^{4}$ We are not claiming that Kimura and Kinchy do not recognize epistemic and practical virtues at all, but rather that they do not recognize them as analytical categories, categories that matter for their theory of participatory research. The same applies to Shirk et al.'s categorization. While they use degree and nature of participation as the main categories for their PR typology, it is clear that they recognize other factors - even Kimura and Kinchy's virtues - as relevant to participatory research. But they do not highlight their central role in the theory of participatory research. We believe that the work of Shirk et al. and Kimura and Kinchy can be synthesized and expanded, resulting in a more

\footnotetext{
${ }^{3}$ Of course, none of this presumes a clean distinction between epistemic and non-epistemic virtues, nor ethical and practical virtues for that matter.

${ }^{4}$ We take this to be a necessary feature of any explanatory or descriptive practice. The topic is discussed at length in (Potochnik 2017).
} 
philosophically general framework for analyzing PR. Our goal in what follows is to develop a more multidimensional analysis that incorporates the central features of these accounts and introduces another consideration that we believe is key to analyzing participatory approaches: divergence of values and goals of the researchers and public participants.

\section{Divergence of Values and Goals}

We begin development of our multidimensional analysis by making explicit a consideration that is left implicit in Kimura and Kinchy's virtue-based account: the perspectival nature of virtues. This can be brought into view by asking: For whom are these virtues? For whom do they provide reasons for engaging in participatory research? It is a philosophical commonplace that reasons can be perspective- or agent-dependent: a good reason for one agent to perform a given action may not be a good reason for another agent to perform the same action. ${ }^{5}$ In Kimura and Kinchy's terms, a virtue for one stakeholder may not be a virtue for another. The virtues exemplified by any given project may depend on the perspective from which that project is analyzed; they may depend on who is doing the analysis and on the nature of her broader values and goals. ${ }^{6}$ In what follows, we will focus on two primary groups of stakeholders involved in all participatory research projects: professionally-trained researchers and members of the participating public.

The perspectival nature of virtues implies that the items on Kimura and Kinchy's list may be viewed differently by professionally-trained researchers and by members of the participating public; and, in fact, they often are. For example, while "increasing scientific data" is a high priority for the designers of Galaxy Zoo (possibly the highest), it is unlikely to be a high priority for most participants. Rather, participants may primarily want to engage in a fun mental activity

\footnotetext{
${ }^{5}$ In this paper we appeal to a broadly Humean understanding of practical action, according to which agents have reasons to act only insofar as their actions promote the satisfaction of their desires and the satisfaction of those desires provides the requisite motivation for undertaking those actions. The action itself is catered to satisfying desire. We use 'goals' as shorthand for the satisfaction of an agent's desires. See (Sinhababu 2009) and references therein.

${ }^{6}$ We should clarify the way in which we use the terms virtues, values, and goals. Following Kimura and Kinchy, virtues are things that PR can achieve, or reasons for choosing PR over other types of scientific research. These need to be pursued or promoted by implementing a certain project design. Values refer to the standards or ideals according to which one determines what is important to them. This is consistent with the term's use in philosophy of science. Goals refer to what one hopes to achieve by participating in a PR project. In our view, these goals depend on one's values and in turn influence what virtues they take a given project to have.
} 
or be part of a larger communal effort. To the extent that increasing scientific data provides a reason for them, it is a fairly weak one (Raddick et al 2009; Raddick et al 2013).

Beyond ranking the relative importance of virtues differently, stakeholders may also categorize virtues differently. Consider two scientists engaged in the same project, one close to retirement and one in her early career. While the former might pursue "increasing scientific data" primarily as an epistemic virtue, the latter might pursue it primarily as a means of career advancement; i.e., what we are calling a 'practical' virtue. The latter would surely recognize that increasing scientific data is also an epistemic virtue of the project, but the virtue may be motivational only or primarily insofar as it is also a practical one. Consider LU-Salud for an example of how this plays out for PR. The original goal of the project was to collect 200 questionnaires from 200 people. But the community participants surpassed that goal, recording 516 questionnaires (Vaughn et al. 2017). From the perspective of the academic researchers, the aspect of the project design that involves the community participants administering the questionnaires to other members of the community clearly promotes an epistemic virtue: participation led to a much larger data sample. From the perspective of the community participants, it seems the project design promotes practical, in addition to ethical, virtues: the data they collected via the questionnaires helped them capture a detailed picture of their community, including health beliefs and practices, and it gave them information about navigating the local healthcare system. The LU-Salud public participants reported feeling empowered by their participation; they feel like a part of social change that will benefit their community (Vaughn et al. 2017, 16).

When multiple aims accompany some set of actions, this picture is further complicated. For example, actions may have different proximate and distal goals. The goals discussed in the above paragraph can be more accurately characterized as distal divergent goals of LU-Salud stakeholders. However, the proximate goal of both researchers and public participants was the same: to collect a large number of questionnaires. It is also possible for two groups to share distal goals and diverge on proximate ones; e.g., when they disagree about how to achieve some particular distal goal. ${ }^{7}$

\footnotetext{
${ }^{7}$ We thank an anonymous referee for suggesting this point.
} 
These short examples demonstrate that what counts as a virtue and how important it is compared to other virtues depends on who is evaluating it and what their larger goals and values are. At an extreme, when the values and goals of scientists and public participants diverge radically enough, they may yield evaluations of the same participatory project that are incompatible, or at least in serious tension with one another (see, for other examples, cases of "narrative mismatch" between researchers and participants (Ottinger 2017)). This divergence is key to our analysis of participatory research.

This is not to say that divergence of values and goals is unique to participatory research -the divergence commonly occurs in traditional scientific research as well. A large research team coming together from different areas of specialization to work on a project at the intersection of their interests is likely to bring to the project a variety of values and goals. But focusing on this aspect of participatory research projects is especially helpful given that the divergence of goals follows directly from the very definition of participatory research as a collaboration among (differently positioned) academic researchers and community participants. Keeping this divergence at the forefront of analysis thus can serve as a fruitful approach for this variety of research.

\section{Norms of Collaboration}

The idea that evaluations of the same project may be incompatible, or at least in serious tension with one another, suggests that good project design ought to try to bring them into harmony with one another, or at least show why their divergence is not problematic. This demand, however, is not unique for participatory research. Rather, it is a broad norm of collaboration that applies to any project. In this section we motivate the idea that PR projects are genuine collaborations and that consequently norms of collaboration play a fundamental role in their analysis and design. We discuss how two general norms of collaboration apply to participatory projects, and suggest that it is more incumbent on the party with more power in a given collaboration to ensure that these norms are attended to.

Let's start by considering whether participatory research projects qualify as collaborations. Some cases are straightforward; these fit Shirk et al.'s category of co-created projects. For example, in LU-Salud, participating members of the community helped conceive, implement, and execute the project. They are referred to as "co-researchers". Other projects 
involve participants in much more limited roles, and researchers may have vastly more control of the project, greater relevant authority, and a tighter connection to the research community. Galaxy Zoo is this kind of project. But both projects (and, in general, projects across the spectrum of participatory research) bear the hallmark characteristics of collaboration: all participants - academic and public_-partake willingly, rely on one another for accomplishing tasks, and work in order to achieve some shared objectives. Below, we will return to the idea that differences in control, authority, reputation, and most generally, power, are also endemic to collaborative relationships. ${ }^{8}$ For now, we merely want to point out that participatory projects can be studied as genuine collaborations, even when a significant power differential exists.

In the literature on norms of collaboration, the focus is often on norms related to authorship credit (see e.g. Youtie and Bozeman 2014, Jeong, Choi, and Kim 2011). For instance, in their discussion of how research collaborations can go wrong, two of the three "bad practices" identified by Youtie and Bozeman (2014) are: “(1) persons not being credited who are perceived as deserving credit, (2) persons being credited who were perceived as not deserving credit" (954). These concerns about unjust credit and unjust lack of credit reflect the general norm that labor should be credited proportionately. In traditional academic collaborations, this norm is usually cashed out in terms of authorship rights or written acknowledgments. However, the generalized norm of proportionate credit for labor applies equally well to participatory research. In participatory projects, authorship and acknowledgment may still be relevant forms of credit, but credit may vary more broadly. For example, credit may be straightforwardly monetary, or take on more nuanced forms of social and political capital. A collaboration that does not heed this norm is likely to run into trouble, if not fall apart entirely. This follows almost trivially from the model of human action we adopt (see footnote 4). If human actions are directed toward goals, then divergence of goals is more likely than not to lead to divergence (and thus conflict) of actions. This is not necessary, of course, but only likely.

\footnotetext{
${ }^{8}$ Additionally, Scientific Collaboration and Collective Knowledge: New Essays edited by Boyer-Kassem, Mayo-Wilson, and Weisberg (2018) offers a collection of papers by philosophers on many of these topics, including the practice of sharing knowledge, forming collaborations, authorship and refereeing, and development of collective credit. This collection primarily focuses on these topics from a traditional academic collaboration perspective. For more on the complexities of volunteer participation in PR, see Reiheld and Gay (2019).
} 
We would also like to call attention to another norm of collaboration, one that has not been widely discussed, but is closely tied to the very idea of collaboration and, to our mind, even motivates the proportionate credit norm. The norm we have in mind is to help fellow collaborators achieve their goals. It is central to our analysis because its satisfaction seems to set the condition of possibility for collaboration itself. After all, without any alignment or compatibility of goals, at least one of the parties will have no reason to engage in the joint endeavor; their participation would have to be forced, unintentional, or irrational. This, again, follows from the model of action we adopt (see footnote 4). On this model, the satisfaction of one (or more) of an agent's goals is her reason for engaging in a given action. Without the prospect of satisfying a goal, the agent has no reason to engage in that action. Consequently, to undertake a collaboration as a collaboration -- a partnership both parties have reason to engage in --, the parties involved must minimally ensure that their goals are, and remain, compatible. This obligation follows from the very nature of collaborative action. In order to meet it, the parties involved must be aware of and affirm the goals of their collaborators. They must also put sufficient effort into achieving those goals, commensurate with their role in the project.

Given that PR projects often involve significant divergence in participants' goals, as discussed in the previous section, this norm requires explicit attention in participatory research contexts. In particular, it can be difficult for academic researchers to assess the goals of the participating public, especially with projects involving many participants or participants who do not interact closely with the researchers. Sometimes conjectures about likely goals will be necessary at the stage of initial research design. Ideally, however, the requirement to be aware of collaborators' goals would be best satisfied with empirical work devised to inform academic researchers' expectations of the goals held by participating members of the public. In many cases, thoughtful design of interactions and inclusion of public participants early in the project can enable this, such as in the initial training sessions incorporated into LU-Salud's project design which emphasized shared decision making (Vaughn et al. 2017, 9; for additional details on LU-Salud project design and considerations see Vaughn et al. 2016 and Jacquez et al. 2016).

Each of these two general norms of collaboration-crediting labor proportionately and helping fellow collaborators achieve their goals_-gives rise to different specific prescriptions that depend on the details of the participatory research collaboration, including the public 
participants' goals, the relationship those goals bear to researchers' goals, and the circumstances of the project. But, we submit, both general norms apply to every PR collaboration, just as they do to traditional academic collaborations. Failure to abide by these norms can lead to a problematic collaboration. For instance, when notable power differentials exist, a project can unwittingly exploit the efforts of its public participants (Reiheld and Gay 2019).

The latter claim highlights again the central role of divergence of goals in the analysis of participatory research. Consider two members of the same research team: a senior researcher whose primary concern is advancing knowledge and a junior researcher whose primary concern is career advancement. This scenario illustrates how power differentials go hand-in-hand with divergences of values and goals: the senior scholar is free to be concerned primarily with advancing knowledge because she is in a position of power. She no longer needs to worry about career advancement. Generally speaking, when parties in a collaboration are similar to one another, their goals are more likely to overlap. Differences between parties, however, may give rise to significantly different relationships to the same project. For example, a collaboration between a senior professor and a graduate student usually gives rise to a greater power differential and a greater divergence of goals than a collaboration between two equally positioned professors. In a fair collaboration, however, a professor recognizes the goals of their student collaborator and facilitates the satisfaction of those goals. The student has matching obligations, but given the power differential, there is typically greater risk of the professor neglecting these norms. We suggest that, in general, as the power differential increases among collaborators, the party with more power has greater responsibility to adhere to the norms of collaboration in order to sustain its nature as a collaboration. ${ }^{9}$

This analysis can be extended to participatory research. Consider Galaxy Zoo through the lens of divergent goals, power differentials, and the constraints they impose on how the norms of collaboration can be satisfied. It is plausible to think that most participants in Galaxy Zoo have the goal of being part of an exciting astronomical research project. Official recognition of their participation might be sufficient to both satisfy this goal and credit their labor appropriately. While the current version of Galaxy Zoo gives users the option of creating an account to track

\footnotetext{
${ }^{9}$ The role of power in scientific research, as well as the relation between academic science and the public good has long been a theme in STS work. See for instance (Kimura and Kinchy 2019; Irwin 1995; Ottinger et al. 2017; Ottinger 2010). See also (Bruner and O'Connor 2018) for discussion of ways in which the divisions systematically disadvantage certain groups in an academic context.
} 
their participation and receive credit, its original incarnation was not set up to do so. Although the following claim is speculative, it is possible that conceiving of this PR project as a collaboration at the design stage might have led to features that would have enabled better assessment and satisfaction of participant goals, and thus the potential for higher participation rates.

In contrast, in LU-Salud, the norms of collaboration were directly attended to in the initial stages of the project. Community team members were considered co-researchers, and the project was designed to incorporate shared decision making at each phase: participants were involved in choosing the research questions and designing the questionnaires, interview and data collection, interpretation of findings, dissemination, and even choosing the compensation for the co-researchers and for questionnaire respondents. By taking on board the input of the community member participants, the design of the project was improved, resulting in a more successful project: for example, the number of questionnaires collected by the co-researchers outpaced expectations significantly (Vaughn et al. 2017).

In summary, given that participatory research is a form of collaboration, it is important to attend to the applicable norms. In general form, these norms include both crediting labor proportionately and helping collaborators achieve their goals. PR projects typically involve both divergent goals and a significant power differential, so attending to the goals and values of the participating public must be a primary consideration, just as proportionate credit is in standard scientific research. Attending to this consideration in the earliest stages of project design can result in a more successful project overall.

\section{From Divergent Goals to Virtues and Types of PR}

In section 3, we emphasized that assessing the relationship between the goals of academic researchers and the goals of public participants is important to analyzing any participatory research project. In section 4, we suggested that because these goals are likely to diverge, norms of collaboration ought to guide how participatory research is designed and undertaken. Here, we suggest that paying attention to how norms of collaboration are applied in the context of divergent goals also yields the set of considerations highlighted by Kimura and Kinchy and Shirk et. al. In other words, we suggest that in our framework, questions concerning how the virtues of 
a PR project are perceived and how the degree of public participation is determined are 'downstream' considerations from questions concerning how to apply norms of collaboration. Once the latter set of questions are answered, clearer and better-founded answers emerge to the first two sets. The participating public's goals, the academic researchers' goals, and the relationship among them helps determine both what degree of public participation is warranted and the epistemic, ethical, and practical virtues the participation gives rise to.

Consider virtues first. Kimura and Kinchy define virtues as the reasons participants have for engaging in a given participatory project. As we discussed in section 3, these reasons only exercise some motivational pull on the person entertaining them if they allow that person to achieve some of their goals. These goals may be narrow (like gaining knowledge of bird migratory patterns) or broad (like living a morally upstanding life), but in our broadly Humean understanding of human action reasons only gain their motivational force by aiming towards the satisfaction of some goal. This suggests that one cannot evaluate the virtues of a given project without recognizing that it may fulfil different goals for different people. For example, if one's goal is to increase social justice, she will view participation in LU-Salud as having sociopolitical virtue. If her goal is only to increase scientific data, an increase in social justice will not be a reason for her to participate in LU-Salud - she will not view it as one of the project's virtues. In this way, the virtues of any given project are 'downstream' considerations, given the values and goals of its participants. Projects developed with norms of collaboration in mind acknowledge the perspectival nature of virtues and so allow different participants to meet their goals and thus find virtue (though not necessarily the same virtue) in any given project.

Consider also Shirk et al.'s five types of participatory research. ${ }^{10}$ They are based on degree of public participation, but, we argue, the appropriate degree of public participation is itself determined by considerations (perhaps implicit ones) regarding the values and goals of members of the research team, and their possible divergence. For instance, contributory projects - designed entirely by academic researchers with public volunteer contributions - may be more appropriate when public participants' goals are primarily aimed at satisfying scientific

\footnotetext{
${ }^{10}$ In what follows we do not extensively discuss collegial projects. However, in collegial projects participants might decide on the goals for the project among themselves. Divergence could arise in later stages (and in fact Shirk et al. note that they might work with researchers to publish data) or between participants. But researchers are likely not involved in project design.
} 
curiosity through being part of an exciting research project (such as Galaxy Zoo). Empirical research would need to bear this out, but out framework suggests that, given these goals, it would be inappropriate to put the public participants in the role of shaping the research aims or design, because it is unnecessary in order for the participants to achieve their goals, and it would require more of them than these goals warrant. In contrast, when a community has intrinsic interest or investment in the research aims or downstream questions about project execution, contributory projects are inappropriate because they violate the norms of collaboration, which, as we are arguing, lead to further complications down the road.

Collaborative projects-designed by academic researchers but enabling the public to have some control of research questions - balance expediency and academic researcher control with some incorporation of community perspective. This type of PR seems appropriate when satisfaction of the participants' goals requires some control over research direction but not full partnership in the research. In instances where there is sufficient overlap in the perspectives of academic researchers and community participants, the academic researchers' project design is likely to meet the goals of the participating public. Contractual projects - when communities engage scientists to conduct the research - are an obvious model if the community participants' goals are more central to the research or do not interfere with academic researchers' goals. Indeed, this codifies in the project design that the researchers' goals stem from or are secondary to the community's goals. Given the typical power differential in PR projects, there is little risk of this approach being used when it violates the norms of collaboration. Our framework predicts this would only happen when the community participants have significantly more relevant power than the academic researchers, which might occur when the participants are governmental or commercial entities.

Finally, co-created projects, in which members of the community are active in all aspects of the research including design and management, afford the participating public and academic researchers equal control of the project. Projects structured in this way make it so that the goals of the participating public can be directly taken into account in developing the project rather than assessed and taken into consideration as a feature of the project. When the power differential is extreme and/or extreme divergence of goals is likely, this can be the most effective way to satisfy norms of collaboration. Community members have a say in identifying the research 
questions, designing the collaboration, conducting the research, and deciding what to do with the results.

The degree of public participation in a PR project will also be shaped by the virtues being pursued by the researchers. These virtues will guide decision-making about project design, which will in turn determine the appropriate degree of public participation and appropriate credit (or compensation). However, in cases where the research itself has potential social or political impact on a community, input from that community should be sought from the beginning. It's possible to think of this as the primary virtue, which should be incorporated into any PR project: Respecting or forwarding the interests or goals of members of the public. There will be many cases where there is no identifiable impacted community, so in those cases the other virtues will determine the degree of public participation. But in cases where such a community exists, a collaborative or co-created project ought to be pursued.

Difficulties may arise in cases where there is significant divergence of goals and values between researchers and participants and researchers fail to incorporate participants' goals into the design of the project, or where there is little or no follow-through on ensuring that participants' goals are met, especially in cases of collaborative or co-created projects. For example, some research projects in the arctic have developed around community partnerships with Indigenous community members who hold extensive, generational knowledge of the region. In a survey of community co-researchers, however, many participants raised a number of concerns for these types of research partnerships (Brunet, Hickey and Humphries 2016). Their concerns included a lack of long-term commitment by academic researchers to partnership development, lack of a sufficient process for dissemination of research results to community members, and inadequate integration of research into action and policy, often a central reason for community members' involvement in the project overall. A general lack of social capital in terms of trust and reciprocity was perceived to be a significant barrier between academic and community researchers. Participants indicated that there was a lack of confidence in community members (on the part of the participating scientists) to conduct research in a professional manner. Similarly, (Eitzel et al. 2017) caution that "outside authorities do not always consider traditional or local knowledge to be legitimate, although these sources of knowledge may be evidence-based and their validity well established" (13). This lack of social capital presents a 
serious issue for successful participatory research projects which rely on the aid of community members.

Addressing how to integrate local and academic knowledge may serve as an important first step in building a successful research partnership between Indigenous communities and academic researchers. Brunet, Hickey and Humphries (2016) suggest that their "results support the need for the early engagement of local partners at the research design and objective setting phases" (352). Indeed, as a result of the survey, policy strategies for conducting future research were developed. These strategies focus on creating funding programs for long-term engagement, ensuring that projects support local autonomy, facilitating educational opportunities for community members, and respecting cultural values and customs. Implementing such strategies in collaborative or co-created projects is essential in order to successfully weave together researcher and community goals.

We've suggested a framework for categorizing participatory research that begins by explicitly considering community and public participants' goals and how those relate to researchers' goals, and then considers a broader range of ethical, epistemic, and practical virtues that result from the participatory work. While detailing strategies for successful PR project design is not our main focus here, we want to briefly draw attention to how the framework we've developed might be brought to bear on the development of participatory projects informed by this framework. We cannot do justice to this topic here, but merely introduce it as a significance for the framework we've developed that deserves investigation in future work. Most basically, if our framework is valuable, this suggests that PR design would benefit from explicitly identifying stakeholders and considering how the research might relate to the values and goals of both the participants and the impacted community. Researchers might also explicitly consider what epistemic, practical, and ethical virtues the project ought to exemplify from their perspective. In conjunction with the norms of collaboration, these considerations may help guide project design.

In summary, we've developed an initial framework for characterizing participatory research that takes into account divergent goals and values between academic researchers and participating members of the public. We've suggested beginning by drawing attention to community and public participants' goals and how those relate to researchers' goals and then considering the broader range of ethical, epistemic, and practical virtues that result from the 
participatory work. This approach is not intended to supplant those offered by Shirk et al. and Kimura and Kinchy, but rather to introduce a new dimension on which PR projects can be characterized. We suggest that investigating how norms of collaboration impact PR work highlights the downstream considerations raised by Shirk et al. and Kimura and Kinchy. We have also argued that projects can have ethical, epistemic, and practical virtues. The relative importance of these virtues may differ when viewing a project through the lens of a researcher in comparison to that of a participant. By explicitly attending to the norms of collaboration outlined in Section 4, namely crediting labor proportionately and helping collaborators achieve their goals, and by attending to the divergence of values in goals in PR more equitable and more successful participatory research can be achieved.

\section{Conclusion}

Participatory research is a form of research collaboration. As with other scientific collaborations, norms of collaboration apply. Thus, participants' various perspectives and goals must be taken into account in the design and implementation of PR projects. This consideration influences what features the collaboration should have. This basic point about norms of collaboration has an important, and perhaps overlooked, implication. Not only should we make explicit the virtues from the perspective of the participants, and how these virtues may diverge from those embraced by the researchers, but the norms of collaboration extending to public participants means that researchers must take into consideration community participants' goals, just as they would for scientist co-researchers.

Our framework is more general than those offered by Shirk et al. (2012) and Kimura and Kinchy (2016). Both of their typologies importantly contribute to our proposed framework, but are combined as downstream considerations after a starting point of explicitly considering the values and goals of public participants in the research. The list of potential virtues participatory research projects may possess is larger and more varied than that offered by Kimura and Kinchy. And in our framework, determining the set of virtues one aims to pursue in a PR project will help guide downstream decisions about level of participation, which encompasses and expands upon the Shirk et al. typology. 


\section{Acknowledgements}

This is a project of the Center for Public Engagement with Science (PEWS) at the University of Cincinnati. All authors contributed equally to the development of the paper, and Martin Rackoff, as an undergraduate intern for PEWS, assisted with research. Thanks to other members of the PEWS Research \& Development Group and the audience of the University of Dayton colloquium Doing Science in a Pluralistic Society for helpful feedback. Our thanks also go to the colloquium organizers and special issue editors, Zachary Piso and Viorel Paslaru, as well as to two anonymous reviewers.

\section{References}

Bonney, R., H. Ballard, R. Jordan, E. McCallie, T. Phillips, J. Shirk, and C. Wilderman. 2009. Public participation in scientific research: defining the field and assessing its potential for informal science education. A CAISE Inquiry Group Report. Center for Advancement of Informal Science Education (CAISE), Washington, D.C., USA.

Boyer-Kassem, Thomas, Conor Mayo-Wilson, and Michael Weisberg, eds. Scientific collaboration and collective knowledge: New essays. Oxford University Press, 2018.

Bruner, Justin, and Cailin O'Connor. "Power, bargaining, and collaboration" in Scientific collaboration and collective knowledge: New essays. Edited by Thomas Boyer-Kassem, Conor Mayo-Wilson, and Michael Weisberg. Oxford University Press, 2018.

Brunet, Nicolas D., Gordon M. Hickey, and Murray M. Humphries. "Local Participation and Partnership Development in Canada's Arctic Research: Challenges and Opportunities in an Age of Empowerment and Self-Determination." Polar Record 52, no. 3 (2016): 345-59.

Cornwall, Andrea. "Unpacking 'Participation': models, meanings and practices." Community development journal 43, no. 3 (2008): 269-283.

Eitzel, M.V, Cappadonna, Jessica L, Santos-Lang, Chris, Duerr, Ruth Ellen, Virapongse, Arika, West, Sarah Elizabeth, Kyba, Christopher Conrad Maximillian, Bowser, Anne, Cooper, Caren Beth, Sforzi, Anea, Metcalfe, Anya Nova, Harris, Edward S, Thiel, Martin, Haklay, Mordechai, Ponciano, Lesano, Roche, Joseph, Ceccaroni, Luigi, Shilling, Fraser Mark, Dörler, Daniel, Heigl, 
Florian, Kiessling, Tim, Davis, Brittany Y, and Jiang, Qijun. "Citizen Science Terminology Matters: Exploring Key Terms." Citizen Science : Theory and Practice 2, no. 1 (2017): 1.

Irwin, Alan. Citizen science: A study of people, expertise and sustainable development. Psychology Press, 1995.

Jacquez, F., Vaughn, L., Zhen-Duan, J., \& Graham, C. (2016). Health Care Use and Barriers to Care among Latino Immigrants in a New Migration Area. Journal of health care for the poor and underserved, 27(4), 1761-1778. https://doi.org/10.1353/hpu.2016.0161

Jacquez, Farrah, Lisa M. Vaughn, and Gabriela Suarez-Cano. "Implementation of a stress intervention with Latino immigrants in a non-traditional migration city." Journal of immigrant and minority health 21, no. 2 (2019): 372-382.

Jeong, S., Choi, J.Y. \& Kim, J. The determinants of research collaboration modes: exploring the effects of research and researcher characteristics on co-authorship. Scientometrics 89, 967 (2011).

Kimura, Aya H., and Abby Kinchy. "Citizen science: Probing the virtues and contexts of participatory research." Engaging Science, Technology, and Society 2 (2016): 331-361.

Kimura, Aya H., and Abby Kinchy. Science by the People: Participation, Power, and the Politics of Environmental Knowledge. Rutgers University Press, 2019.

Moore, K. 2006. "Powered by the People: Scientific Authority in Participatory Science." Book Section. In The New Political Sociology of Science, edited by Scott Frickel and Kelly Moore, 299-323. Madison: University of Wisconsin Press.

Ottinger, Gwen. "Buckets of resistance: Standards and the effectiveness of citizen science." Science, Technology, \& Human Values 35, no. 2 (2010): 244-270.

Ottinger, Gwen. "Making sense of citizen science: stories as a hermeneutic resource." Energy research \& social science31 (2017): 41-49.

Ottinger, Gwen, D. Tyfield, R. Lave, S. Randalls, and R. Thorpe. "Scientific authority and models of change in two traditions of citizen science." The routledge handbook of the political economy of science 351 (2017): 9781315685397-31. 
Raddick, M. Jordan, Georgia Bracey, Pamela L. Gay, Chris J. Lintott, Phil Murray, Kevin Schawinski, Alexander S. Szalay, and Jan Vandenberg. "Galaxy zoo: Exploring the motivations of citizen science volunteers." arXiv preprint arXiv:0909.2925(2009).

Raddick, M. Jordan, Georgia Bracey, Pamela L. Gay, Chris J. Lintott, Carie Cardamone, Phil Murray, Kevin Schawinski, Alexander S. Szalay, and Jan Vandenberg. "Galaxy Zoo:

Motivations of citizen scientists." arXiv preprint arXiv:1303.6886 (2013).

Reiheld, Alison and Pamela Gay. "Coercion, Consent, and Participation in Citizen Science." arXiv preprint arXiv:1907.13061 (2019).

Neil Sinhababu, "The Humean Theory of Motivation Reformulated and Defended," Philosophical Review 118 (2009): 465-500.

Shirk, Jennifer L., Heidi L. Ballard, Candie C. Wilderman, Tina Phillips, Andrea Wiggins, Rebecca Jordan, Ellen McCallie et al. "Public participation in scientific research: a framework for deliberate design." Ecology and society 17, no. 2 (2012).

Sullivan, Brian L, Christopher L Wood, Marshall J Iliff, Rick E Bonney, Daniel Fink, and Steve Kelling. "eBird: A citizen-based bird observation network in the biological sciences." Biological Conservation 142, 10 (2009): 2282-2292.

Vaughn, L.M., Jacquez, F., Marschner, D. et al. See what we say: using concept mapping to visualize Latino immigrant's strategies for health interventions. Int J Public Health 61, 837-845 (2016). https://doi.org/10.1007/s00038-016-0838-4

Vaughn, L. M., Jacquez, F., Zhen-Duan, J., Graham, C., \& Marschner, D. (2017). Latinos Unidos por la Salud: The Process of Developing an Immigrant Community Research Team. Collaborations: A Journal of Community-based Research and Practice, 1(1), 2.

Vaughn, L. M., \& Jacquez, F. (2020). Participatory Research Methods - Choice Points in the Research Process. Journal of Participatory Research Methods, 1(1).

https://doi.org/10.35844/001c. 13244

Wiggins, Andrea, and Kevin Crowston. "Developing a conceptual model of virtual organisations for citizen science." International Journal of Organisational Design and Engineering 1, no. 1-2 (2010): 148-162. 
Youtie, Jan, and Barry Bozeman. "Social dynamics of research collaboration: Norms, practices, and ethical issues in determining co-authorship rights." Scientometrics 101, no. 2 (2014): 953962. 